1 Faculdade de Ciências Médicas da Santa Casa de São Paulo (FCMSCSP) São Paulo (SP), Brasil. d.fig94@gmail.com

2 Universidade Federal de São Paulo (Unifesp), Centro de Desenvolvimento do Ensino Superior em Saúde (Cedess) - São Paulo (SP), Brasil.

3 Universidade de São Paulo (USP), Faculdade de Saúde Pública - São Paulo (SP), Brasil.

4 Pontifícia Universidade Católica de São Paulo (PUC-SP), Programa de Estudos Pós-Graduados em Economia Política - São Paulo (SP), Brasil.

\section{A Reforma Sanitária Brasileira e a natureza do Estado: apontamentos críticos sobre a questão agrária}

\author{
Brazilian Sanitary Reform and the nature of the State: critical notes \\ on the agrarian issue
}

Daniel Figueiredo de Almeida Alves', Leonardo Carnut2, Áquilas Mendes ${ }^{\mathbf{3}, \mathbf{4}}$

DOI: 10.1590/0103-11042019S819

RESUMO Desde o nascedouro do movimento da Reforma Sanitária Brasileira, seus intelectuais apresentavam uma leitura particular sobre o papel do Estado na formação social e sobre o desenvolvimento das forças produtivas. A análise desta visão é fundamental para o entendimento dos limites do aparelho de Estado na opção política realizada pelo movimento. Este estudo, portanto, tem como objetivo debater criticamente com as formulações acerca da natureza do Estado, a categoria 'cidadania' e suas especificidades em países subdesenvolvidos. Utiliza-se deste percurso crítico para analisar a práxis da Reforma Sanitária e as relações entre saúde e questão agrária no Brasil. Para tanto, optou-se pela modalidade textual do tipo ensaio. De modo geral, a natureza do Estado em países subdesenvolvidos pode ser repensada a partir da economia mundial. Essa natureza desvela a função estatal de (re)produtor das relações capitalistas, caracterizada por uma violência particular apresentada politicamente na forma-regime de 'legitimidade restrita'. Essa violência está intimamente ligada às relações de exploração no campo e são essenciais para o desenvolvimento da acumulação capitalista. Este argumento parece importante para repensar a centralidade da questão agrária no movimento sanitário.

PALAVRAS-CHAVE Estado. Capitalismo. Saúde pública. Reforma dos serviços de saúde. Saúde rural.

ABSTRACT Since the birth of the Brazilian Sanitary Reform movement, its intellectuals presented a particular reading about the role of the State in the social constitution and development of the productive forces. The analysis of this view is fundamental for understanding the limits of the State apparatus in the political choice made by such movement. Therefore, this study aims to critically debate with the formulations about the nature of the State, the category of 'citizenship' and its specificities in underdeveloped countries. This critical path is used to analyze the Sanitary Reform praxis on the relationship between health and agrarian issues in Brazil. Thus, we opted for the textual type of an essay. Overall, the nature of the State in underdeveloped countries can be rethought from global economy. That nature imposes on the State the role of (re)producer of capitalist relations, characterized by a particular violence politically presented in the form-regime of restricted legitimacy. Such violence is closely linked to exploitative relations in the countryside and is essential in the development of capitalist accumulation. This argument seems to be important to rethink the centrality of the agrarian issue within the sanitary movement.

KEYWORDS State. Capitalism. Public health. Health care reform. Rural Health. 


\section{Introdução}

Com o processo de redemocratização na transição de regime político da ditadura civil-militar-empresarial para a Nova República, as diversas lutas sociais exigiam da centralidade da questão social uma busca pela legitimação de orientação democrático-popular. Entre estas lutas, a Reforma Sanitária Brasileira se insere nesse contexto enquanto movimento de base técnica e intelectual ${ }^{1}$, majoritariamente representada pela atuação de sanitaristas filiados ao Centro Brasileiro de Estudos de Saúde (Cebes) e à Associação Brasileira de Saúde Coletiva (Abrasco), e, em certa medida, de base popular exemplificada pela atuação do Movimento Popular em Saúde (Mops)², Movimentos Eclesiais de Base, e diversos grupos menores de trabalhadores e sociedade civil organizados autonomamente. Uma das particularidades do movimento da Reforma Sanitária foi, em certa medida, o emprego de categorias centrais da tradição marxista e de atuação de inspiração socialista para compor o entendimento da conjuntura em que se encontravam. O emprego dessas categoriais contribuiu sobremaneira para aprofundamento das análises sobre o contexto brasileiro da luta de classes em que os reformistas estavam.

Com esse intuito, compreendemos que a obra de Sonia Fleury Teixeira ${ }^{3}$ é uma das principais contribuições teóricas acerca da atuação tático-estratégica do movimento sanitário, mesmo considerando que as contribuições dessa autora não esgotam a pluralidade ${ }^{4-7}$ de interpretações sobre a conjuntura nem sobre os caminhos da reforma por diversos outros intelectuais de grande monta. Contudo, em virtude do curto espaço para uma reflexão mais diversa sobre as disputas interpretativas realizadas por seus intelectuais e movimentos sociais, elegemos Fleury por considerá-la a principal articuladora desses intelectuais e, ainda, por deter formação teórica densa em ciência política com foco no Estado $^{8}$, objeto de nossa análise.

Entre a vasta obra da autora, reconhecidamente produtora de uma 'teoria da Reforma
Sanitária', consideramos que o que mais sintetiza a elaboração original que conduziu o movimento aos caminhos que percorreu em seu percurso é o texto de sua madurez 'Reflexões teóricas sobre democracia e reforma sanitária', publicado pela editora Cortez em $1989^{3}$. Ele nos serviu de base para alçar reflexões a respeito do pensamento político produzido naquele momento, e um possível diálogo, ainda que com restrições temporais, sobre como podemos pensar a interpretação de suas categorias centrais em articulação à questão agrária no Brasil.

Assim, reforçamos que, dentre estas contribuições que Fleury nos brinda, destacamos o prolífico debate sobre a natureza do Estado e sua derivada importância na luta pela construção de uma contra-hegemonia. Esse debate, dentro da conjuntura na qual se encerrava, apontava para a cidadania enquanto tática e estratégia de edificação de um consenso social que poderia levar ao acirramento das contradições entre as classes na sociabilidade capitalista e que - profundamente influenciadas pelas formulações de Coutinho ${ }^{9}$ - aliam-se à tese da democracia enquanto valor universal, conforme revisada por Neves ${ }^{10}$ e cuja evidência histórica entre Fleury e Coutinho foi demonstrada por Dantas².

Com o patente processo de burocratização da Reforma Sanitária e da possibilidade de inflexão de regime político, porém, ambas as contribuições - natureza do Estado e a categoria 'cidadania' - devem ser colocadas sob as lentes da crítica; justamente pela compreensão de que essas são categorias centrais no conteúdo e forma de atuação do movimento sanitário, o que possibilita realizar um balanço dos limites imanentes destas para orientação de uma práxis transformadora aliada à perspectiva da determinação social da saúde ${ }^{11}$.

É pertinente pontuar que, neste ensaio, não se trata de questionar o uso das táticas e estratégias políticas usadas pelos atores-autores da Reforma Sanitária em termos de uma 'incompreensão teórica' ou da 'desconsideração da natureza específica da formação social e política dos países 
subdesenvolvidos', mas, sim, de entender como uma articulação entre a questão agrária (como epicentro da disputa capital-trabalho) e Reforma Sanitária pode ser tematizada.

Neste momento, recordamos que este ensaio visa, apenas, uma análise teórica da Reforma Sanitária circunscrita ao exame de um único texto de uma autora por reconhecer sua relevância para o movimento, e não com pretensões de generalizar sua perspectiva, já que o movimento da reforma, como dito antes, é bastante plural. Assim, a análise aprofundada do texto da autora (que possui várias outras formulações articuladas que não são apresentadas ao leitor) foram escolhidas por tematizar diretamente as categorias sob reflexão neste ensaio, o que, em si mesmo, já é um esforço louvável em repensar a teoria.

Dessa maneira, ante a problemática apresentada, o presente ensaio tem como objetivo debater criticamente com as formulações acerca da natureza do Estado, a categoria 'cidadania' e suas especificidades em países subdesenvolvidos e de inserção dependente, utilizando, para isso, do percurso crítico para analisar a práxis da Reforma Sanitária sobre as relações entre saúde e questão agrária no Brasil.

\section{Reforma Sanitária e natureza do Estado}

Primeiramente, devemos nos debruçar com mais atenção sobre as análises empreendidas sobre a natureza do Estado e suas especificidades em países de inserção dependente na economia mundial12,13.

A interpretação de Fleury ${ }^{3}$, realizada com intuito de buscar uma teoria para o movimento, contribui para o correto desenvolvimento da análise que a natureza do Estado capitalista não pode ser mecanicamente interpretada como uma extensão da vontade das classes dominantes. Como vemos nas duas citações a seguir:

A compreensão do Estado, não mais como exclusivamente um comitê de negócios da burguesia, mas como arena de lutas políticas crivada das contradições que atravessam a estrutura de classes tem como correspondente a identificação de que o poder passa tanto pela direção/dominação hegemônica quanto pela coerção3(31).

É certo que a compreensão do Estado como uma relação que se cristaliza materialmente (Poulantzas, N., 1980) deixa claro que qualquer transformação na estrutura de poder não poderá se reduzir ao nível da luta política, mas deverá ser também materializada sua ossatura material do Estado. Mas, para além de uma materialização do poder, o Estado, todas as suas instâncias materiais passam a ser vistas como arena política. A estratégia de construção da hegemonia em Gramsci concentrava-se na esfera da sociedade civil, mas os estudos recentes, especialmente de Poulantzas, colocam a sociedade política, o Estado no sentido estrito, no seio da luta de classes ${ }^{3(43)}$.

Fleury ${ }^{3}$ nos adverte que as intepretações do Estado à luz da vertente funcionalista-estruturalista do marxismo são insuficientes, indo em direção a uma perspectiva mais poulantziano-gramsciana do debate ${ }^{\mathbf{1 4}}$. Em nossa análise, essa abordagem, ainda em ancoradouro marxista, apresenta limites no que tange à devida mediação entre as categorias 'capital' e 'economia mundial constituída'. Mesmo considerando que a autonomização relativa da esfera política em relação à econômica é uma crítica marxiana importante ${ }^{15}$, do ponto de vista teórico, a falta da 'economia mundial' pode equiparar a natureza de ambos os Estados capitalistas de países desenvolvidos e subdesenvolvidos, como se ambas as categorias derivassem da mesma dedução lógica e histórica ${ }^{16}$.

Ora, segundo Mathias e Salama ${ }^{16}$, a dedução lógica da natureza do Estado capitalista de países desenvolvidos e subdesenvolvidos perpassa uma sequência de categorias diferentes. Essas diferenças têm implicações determinantes em suas funções fundamentais e na forma de suas existências, ou seja, alteram 
drasticamente a conformação dos regimes políticos e suas decorrentes necessidades de legitimação, o que torna necessário, para a qualificação do debate, uma apresentação mais detalhada de ambos os casos.

Dessa maneira, antes de analisarmos a natureza do Estado presente no contexto brasileiro, o estudo dessa natureza em países desenvolvidos ajuda na compreensão mais acertada dessa realidade. Como proposto, no caso dos países desenvolvidos, devido ao desenvolvimento do capitalismo por mecanismos endógenos (dedução histórica da formação do Estado-nação ${ }^{17}$ ), é cabível deduzir a categoria Estado diretamente da categoria capital ${ }^{16}$. A partir desse entendimento, o Estado não é uma simples superestrutura política que se remete em última instância ao econômico ${ }^{\mathbf{1 4}}$, mas, sim, tem um papel fundante nas relações de produção e da sociabilidade burguesa, permite a realização do valor das mercadorias no âmbito da circulação e ocupa-se da socialização da reprodução da força de trabalho.

Antes de criar as relações de produção tipicamente capitalistas, o Estado também tem um papel fiador. $\mathrm{O}$ fetiche da mercadoria ${ }^{18}$ torna-se realizável em conjunto com o fetiche do sujeito de direito ${ }^{19}$, ou seja, a produção e a troca de mercadorias tornam-se possíveis, e, em termos políticos, com a noção moderna de 'emancipação política'20, isto é, de cidadania. Em suma, temos que a natureza do Estado em países desenvolvidos também é dependente do papel de fiador das relações de produção capitalista e de reprodução das condições de regeneração da força de trabalho a partir das necessidades ampliadas da acumulação.

Esclarecendo: não houve nenhum processo de formação de relações capitalistas de produção sem o papel ativo e mesmo violento do Estado. Quer dizer, os Estados dos países desenvolvidos ou centrais também impuseram de 'fora' relações capitalistas às suas populações. Eles não apenas se comportaram como 'fiadores' de relações capitalistas preexistentes, mas desempenham esse papel. Ademais, 0 próprio surgimento do capitalismo nos países centrais também se deveu (e daí assinalar a centralidade do papel da terra e sua disputa) ao processo específico de sua formação social nos países centrais. Esse processo não explica apenas a formação capitalista no 'sul global', como costuma se dizer hoje, mas também no 'norte global'.

Em países subdesenvolvidos, contudo, a categoria Estado não pode ser tão deduzida da categoria capital ${ }^{16}$ quanto em países de capitalismo central. Diferentemente dos países desenvolvidos, as relações de produção e a sociabilidade burguesa são exógenas à formação social, que foi imposta a partir da violência colonial e neocolonial sobre os países da América Latina, Ásia e África21,22. Portanto, as categorias capital e Estado são mediadas, nesse caso, pela economia mundial constituída. É importante dizer que, na análise de Mathias e Salama ${ }^{16}$, trata-se de uma 'dedução lógica' e que não se trata de uma chave esquemática de análise, mas, sim, uma forma de entendimento do processo de derivação dos Estados em países subdesenvolvidos a partir de sua forma jurídica. Logo, isso é apenas uma dimensão da compreensão, que, longe de distorcer aspectos fundamentais do processo histórico de formação dos Estados tanto no centro como na periferia, tenta adjudicar mais elementos a essa intepretação.

Temos que a divisão internacional do trabalho molda a natureza do Estado e condiciona a determinação deste aos ditames da acumulação do capital em nível mundial. Dessa maneira, vemos que, nesses países, antes mesmo de haver relações de produção capitalistas, já havia um Estado capitalista; nesse caso, o Estado é responsável pela criação dessas relações. Sua natureza e sua legitimação do regime político se ancoram no forjar das relações de produção capitalistas, majoritariamente desenvolvidas pelo uso da violência. Esta, por consequência, gera uma maior preponderância do trânsito entre trabalho formal e informal (ou seja, de uma economia doméstica do trabalho que se sobrepõe as formas clássicas - e protegidas 
- das relações de trabalho) ou, ainda, nos termos de Matias e Salama: 'socialização doméstica da força de trabalho'16.

A partir dessa breve apresentação da problemática, ficam evidentes as limitações em equalizar a natureza do Estado brasileiro ao de países desenvolvidos. De fato, o Estado brasileiro não é uma 'correia de transmissão' dos interesses das classes dominantes locais, contudo, também não é um ente neutro, ou terreno estéril de intencionalidades que encontram na sua forma política ancoradouro para reproduzir mais facilmente os interesses das frações de classes dominantes.

O Estado, em sua natureza, ou, ainda, em sua ossatura jurídico-política, possui elementos que garantem, em última instância, a reprodução da sociabilidade capitalista. No caso dos países subdesenvolvidos, esses elementos são forjados pela inserção desse Estado na economia mundial constituída em seu nascedouro, cujo modo de dominação é majoritariamente baseado na 'violência de classe' objetivada para forçosamente criar relações de produção capitalistas. Isso reforça a tese de que as bases populares, por mais resistências que ofereçam, parecem não ser o suficiente para construção da legitimidade popular que opere na construção de um Estado com finalidade nacional, uma vez que a legitimidade para justificar o Estado advém da 'forma-regime' ou, em outras palavras, dos 'regimes políticos' que garantam o Estado em sua condição de subordinação aos países centrais.

Visto que, na especificidade da natureza do Estado de países subdesenvolvidos, a democracia, que não é um valor universal23, mas, sim, um acidente de percurso, dá-se no desenvolvimento da categoria cidadania enquanto tática e estratégia, tão cara ao movimento sanitário ${ }^{2,3}$, devendo-se o Estado ser analisado por essa 'dedução lógica' e por suas derivações na forma de regime político.

Nas elaborações de Fleury ${ }^{3}$, o desenvolvimento histórico da categoria da cidadania pode ser entendido enquanto contradição dialética. Promove a mistificação da consciência das classes dominadas pela igualdade formal na sociabilidade burguesa - condicionante essencial para a ideologia liberal do Estado - e, ao mesmo tempo, foi necessária para organização do movimento operário. Temos que a seguinte citação exprime essa dialética:

Este efeito de mascaramento é responsável pela reprodução social na medida em que a condição de cidadania passa a ser o fundamento do dever político, ampliando o consenso relativo à ordem política, 'reservando assim à coerção física uma posição permanente, porém virtual'. No entanto, se por um lado a cidadania enquanto relação individual de direito entre o cidadão e o Estado, é a negação da existência das classes sociais, por outro lado, seu reconhecimento, contraditoriamente, foi imprescindível para a constituição, organização e luta das classes dominadas 3(21). [grifo nosso].

Concordamos com as elaborações da autora sobre a unidade contraditória da categoria cidadania, porém, essas formulações aplicam-se com mais fidelidade à natureza do Estado em países desenvolvidos, podendo-se aproveitar apenas de parte dessa compreensão sobre os mecanismos de legitimação e coerção em âmbito subdesenvolvido, especialmente no contexto brasileiro.

Para refinar melhor esta análise, fazem-se necessários alguns esclarecimentos de ordem contextual e paradigmática. Entendemos que Fleury, ao adotar um ponto de vista socialdemocrata, considera como coerção física a ação de violência deliberada do Estado sobre seus cidadãos. Em função do regime ditatorial próprio da conjuntura vivenciada na elaboração deste texto, este trecho nos reserva a ideia de que a violência política não existiria em condições de normalidade democrática (ou, em suas palavras, a violência seria apenas 'virtual', ou seja, paira no ar como um tom de 'ameaça').

No entanto, sob uma interpretação marxista deste trecho, a coerção física proporcionada pelo Estado (inclusive no período da ditadura) 
não passa de uma das diferentes formas de violência objetiva que o Estado moderno realiza para manutenção da sociabilidade capitalista. Em outros termos, o que se critica é que há presença de violência, mesmo quando sob um regime político democrático-liberal (que não há nada de virtual nisto), pois a própria democracia (burguesa) é uma forma de legitimar a violência do Estado moderno sob outras formas de sociabilidade que não sejam capitalistas. Dito isto, parece então prudente assinalar que a defesa da cidadania, mesmo sob os ventos de transição democrática, apresenta limites do ponto de vista tático de um movimento que se dizia, até então, em busca do socialismo.

Assim, conforme a mediação que viemos construindo para compreender o Estado em países subdesenvolvidos, a violência objetiva é aguçada (ou fica explícita) nesses países quando a forma-regime (forma jurídica essencial) assume um caráter restritivo. Em outras palavras, é um fator central nesses países a criação de regimes políticos de legitimidade restrita, tais quais as formas do Estado brasileiro assumiram para destravar a acumulação capitalista visto em âmbito de sua inserção na economia mundial ${ }^{24}$. Esse regime, à época, foi a ditatura militar-empresarial entre 1964 e 1984. Hoje, podemos dizer que é uma espécie de democracia blindada 25 .

Para aprofundar a qualificação do debate proposto, não podemos somente nos remeter, em plano abstrato, à dedução lógica das categorias. A dedução histórica é fundamental para o entendimento do descompasso entre a tática e a estratégia da Reforma Sanitária Brasileira para com a natureza do Estado em países subdesenvolvidos. Para tanto, os estudos sobre o 'capitalismo dependente' promovidos por intelectuais brasileiros são incontornáveis.

Em linhas gerais, a questão da dependência não pode ser explicada somente pela posição de colônia no processo sócio-histórico de formação brasileira, mas, sim, pela subserviência das classes dominantes perante a economia mundial constituída ${ }^{12}$ - economia esta que não surge a partir da 'livre troca' de mercadoria entre nações, mas pela violência imperialista ${ }^{26}$. Ou seja, a burguesia supostamente nacional, desde o seu nascedouro, não apresenta interesse para romper com a dependência e desenvolver as forças produtivas com finalidade nacional. Pelo contrário, revela um longo histórico de 'modernizações conservadoras' com intuito de abafar e manter sua dominação sobre os 'de baixo'27.

Essa tendência histórica de manutenção da ordem vigente implica na particularidade específica do capitalismo dependente. $\mathrm{O}$ aprofundamento das relações de produção capitalistas não se traduz, linearmente, em nenhum caso, muito menos nos países subdesenvolvidos, cujo florescimento das forças produtivas, na maior parte das vezes, não se expressa em melhorias das condições de vida das classes dominadas. Nessa dinâmica dependente, a existência do 'arcaico' e da superexploração é uma condição necessária para engendrar o moderno ${ }^{12,28}$ - configurando a formação social brasileira em um verdadeiro mosaico de relações de produção e de tempos históricos.

Como ilustrado por Oliveira ${ }^{29}$, no período de maior industrialização brasileira - compreendida nos planos desenvolvimentistas de Juscelino Kubitschek -, houve uma diminuição real do salário dos trabalhadores urbanos; acompanhada de uma expansão da 'informalidade', 'socialização doméstica da força de trabalho' e relações 'não-capitalistas' de produção no campo - que, apesar de não serem capitalistas, são parte constituintes da totalidade social imposta pela divisão internacional do trabalho.

No entanto, somente isso não é o suficiente para entender a dinâmica da dependência que particulariza o papel do Estado brasileiro. Para Mathias e Salama ${ }^{16}$, a falta de interesse da burguesia brasileira e suas frações podem ser compreendidas pelo papel em que jogam na assunção dos interesses imperialistas em utilizar o Estado brasileiro para mantê-las em sua posição de classe. O Estado brasileiro tem, em sua gênese, a mescla entre unidade 
doméstica e unidade de produção. Isso significa dizer que não são as classes dominantes brasileiras, nos diversos tempos históricos, que engendram e cristalizam as relações capitalistas. Elas ajudam, mas não detêm a autoria. É o Estado que as (re)produz em associação com o Estado e os interesses da burguesia dos países de capitalismo central16.

Mathias e Salama ${ }^{16}$ bem explicam essa dialética. Para os autores, a intervenção estatal nos países subdesenvolvidos se legitima pelo investimento em infraestrutura e em setores estratégicos dos ramos industriais (ou de 'base'), pois necessitam 'abrir espaço' para as formas iniciais de exploração capitalista. Já nos países desenvolvidos, a intervenção estatal se legitima devido ao desenvolvimento de uma 'gestão estatal da força de trabalho' (previdência social, alocações diversas etc.), que tem como função precípua regenerar a força de trabalho.

Desse modo, em países desenvolvidos, o Estado tem na ideia de 'cidadania' os elementos para o controle e manutenção da ordem burguesa podendo ser expressa em sua máxima sofisticação. Ele pode operar o 'protocolo democrático' (sufrágio universal, eleições periódicas e universalidade das liberdades civis) com certa clareza e completude na vida social, já que esses elementos são as formas de dominação já estabelecidas, 'consensuadas', com o mínimo de violência por meio da repressão física continuada. Isto é a regra.

Nos países subdesenvolvidos, a regra é outra. É a incompletude dos 'protocolos' da democracia burguesa, ou, em outras palavras, a sua instabilidade que vigora. É necessário que seus fundamentos sejam, na prática, frágeis ou incipientes para que se justifique o 'peso' da intervenção estatal na tentativa (quase sempre bem-sucedida) de impor o modo de produzir capitalista; nem que seja por meio da violência clara e concreta, de forma sistemática e continuada. Por isso, o regime político (como a ditadura, por exemplo) é um aliado importante nesse processo, especialmente quando há entraves na acumulação ampliada do capital, ou, ainda, resistência popular organizada.
Nesse contexto, podemos dizer que a violência é uma das marcas constitutivas da sociabilidade capitalista, e não uma posição 'virtualizada'. Em ambos os casos (países desenvolvidos e subdesenvolvidos) há violência. É assim que a dialética da cidadania 'pende' com maior intensidade para a 'mistificação da consciência da classe trabalhadora' do que no sentido de organizá-la, pois, ao enfatizar a democracia como estratégia para o movimento da Reforma Sanitária, a produção de consciência social sobre a violência no capitalismo ${ }^{30} \mathrm{e}$ o reconhecimento da classe enquanto sujeito histórico da transformação social ${ }^{31}$ ficam comprometidos. Assim, reconhecendo o logro para aquele momento, mas no sentido de avançar no debate da Reforma Sanitária, é essencial reconhecermos os limites claros dessa tática e estratégia, sobretudo, baseados na leitura do Estado nos dias de hoje.

Uma vez apresentadas as diferentes naturezas do Estado capitalista e suas implicações sobre a categoria cidadania, propomos, para a próxima sessão, uma análise materialista e dialética ${ }^{32}$ da relação entre a questão agrária, Reforma Sanitária e saúde - compreendida enquanto necessidade radical do ser social ${ }^{33,34}$. A questão agrária é central para o entendimento consistente da dinâmica de acumulação capitalista no Brasil12,16,21,35; além de estar intimamente ligada à reprodução social da dialética saúde-doença ${ }^{36,37}$.

\section{A conformação histórica da questão agrária no Brasil e sua centralidade para Reforma Sanitária}

A questão agrária é central para a compreensão não somente da dinâmica de acumulação capitalista ${ }^{35}$ em países de inserção dependente e de características subdesenvolvidas, mas também para o desenvolvimento dos países de capitalismo central, sendo essa relação mediada pela economia mundial constituída. 
Nas formulações de Marini12, o próprio desenvolvimento manufatureiro e industrial de países de capitalismo central é, em parte, devido ao excedente da produção de origem agropecuária oriundos, significativamente, da América Latina. Essa dinâmica de especialização da produção de mercadorias, em condição de deterioração dos termos de troca, possibilitou a cristalização da divisão internacional do trabalho e, em seu decurso, intensifica a dinâmica da dependência. Como vemos na citação a seguir:

A criação da grande indústria moderna seria fortemente obstaculizada se não houvesse contado com os países dependentes e tido que se realizar sobre uma base estreitamente nacional. De fato, o desenvolvimento industrial supõe uma grande disponibilidade de produtos agrícolas, que permite a especialização de parte da sociedade na atividade especificamente industrial. No caso da industrialização europeia, o recurso à simples produção agrícola interna teria bloqueado a elevada especialização produtiva que a grande indústria tornava possível. O forte incremento da classe operária industrial e, em geral, da população urbana ocupada na indústria e nos serviços, que se verifica nos países industriais do século passado, 'não poderia ter acontecido se estes não contassem com os meios de subsistência de origem agropecuária, proporcionado de forma considerável pelo países latino-americanos'. Isso foi o que permitiu aprofundar a divisão do trabalho e especializar os países industriais como produtores mundiais

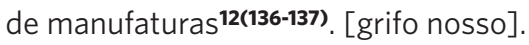

Consequentemente, o aprofundamento dessa especificidade é a característica essencial da acumulação capitalista no Brasil. Ou seja, dependência que somente gera mais dependência ${ }^{\mathbf{2}}$. Nesse quesito, a questão agrária é o veio condutor desse processo e é o que unifica a América Latina como um bloco econômico.

Historicamente, as relações de produção no campo que poderiam ser classificadas como 'não-capitalistas', ou seja, relações de produção que não apresentam como característica majoritária a generalização do assalariamento (a forma-mercadoria da força de trabalho), possibilitaram, em boa medida, a parcial industrialização urbana em momentos favoráveis da conjuntura internacional16. Como exemplifica Oliveira ${ }^{29}$, a solução do chamado 'problema agrário' nos anos de inflexão da economia de base agrário-exportadora para urbano-industrial é uma condição fundamental para o processo de (re)produção ampliada do capital. Essa solução tem como um ponto fundamental a constante expansão da ocupação de terras com baixíssimos níveis de capitalização e, de certa maneira, opera como uma 'acumulação primitiva' - que, nas especificidades do subdesenvolvimento, é estrutural, não somente 'genética'. Portanto, devido ao cultivo de subsistência nas zonas de expansão, esse mecanismo rebaixa os preços dos produtos das lavouras destinadas ao consumo interno (sobretudo do crescente contingente urbano).

Em outras palavras, a característica estrutural da 'acumulação primitiva' no subdesenvolvimento tem importantes repercussões, tanto nas relações de produção no campo quanto na esfera agrária-urbana. No primeiro caso, esta acumulação é responsável pela formação de uma força de trabalho que serve às culturas comerciais do mercado interno e externo. No segundo caso, também devido ao rebaixamento do custo real da alimentação (determinado pela reprodução desta força de trabalho rural) a acumulação primitiva desenvolve um importante papel na perpetuação dos baixos custos de reprodução da força de trabalho urbana $^{29}$, consequentemente possibilitando uma maior extração de mais-valia relativa. Este mecanismo permite a remessa de mais-valor para o centro desenvolvido, permitindo maior acumulação de capital no centro e a manutenção da taxa de lucro condizentes com uma industrialização parcial na periferia.

É necessária, porém, uma mediação entre a economia mundial constituída, as relações de produção 'não-capitalistas' no campo e 
a industrialização urbana. Essa mediação é o Estado. Por meio de sua forma, o regime político, atua não somente como fiador dessa relação, mas como o seu produtor direto ${ }^{16}$. Dessa maneira, o que antes era determinado pelo 'exterior', é internalizado pela natureza do Estado.

Essa atuação é mediatizada pela violência; por meio desta, o Estado 'moderniza' as relações 'não-capitalistas'. Entretanto, essa é ainda uma 'tarefa' inconclusa. Esse processo é exemplificado nas citações a seguir:

[...] O desenvolvimento do capitalismo, portanto, não se processava endogenamente mediante a resolução e superação das contradições, mas resultava essencialmente de uma agressão contra as relações comunitárias. Mais tarde, esse 'exterior' passou a ser representado pelo próprio Estado. O Estado coloca-se fundamentalmente na origem do impulso a esse processo de modernização, mesmo quando esse último - faz-se acompanhar por uma elevação dos custos. Esse paradoxo é assim revogado pelo papel assumido pela política do Estado. Essa, finalmente, encontra seu fundamento não numa exterioridade total, mas - de fato e como já sabemos - no que faz desses Estados, nos países subdesenvolvidos, Estados capitalistas. 'O Estado, com efeito, é o lugar e o meio de difusão das relações mercantis num contexto não-capitalista'16(108). [grifo nosso]

[...] O assalariamento é o produto de uma modificação das estruturas agrárias, de uma monetarização das condições de reprodução da força de trabalho, modificação e monetarização que não poderiam se realizar sem a intervenção direta ou indireta do Estado. A violência estatal assume assim outras formas que não as que pôde ter antes. 'É a pré-condição e o suporte da penetração das relações mercantis no campo. $O$ assalariamento é o produto mediatizado da violência no campo'16(110). [grifo nosso].

Por sua vez, essa mudança de relação de produção de forma 'drástica' ou 'acelerada'
- característica do subdesenvolvimento - leva a uma intensa deterioração das condições de vida dos trabalhadores campesinos. Apesar de empregar modernas técnicas e de aumentar a produtividade, encurta a vida dos camponeses. Primeiramente, a modernização leva à especialização da produção, e uma maior parcela da terra é destinada para este fim, o que restringe a produção de cunho autossuficiente e promove o assalariamento e a monetização. Em segundo lugar, a especialização da produção não é direcionada, necessariamente, ao mercado interno, mas, sim, às necessidades impostas pela divisão internacional12. Dessa maneira, engendra-se uma relação contraditória: modernização com aumento progressivo dos custos; aumento da produtividade com recrudescimento das condições de vida e intensificação da fome como um fenômeno social. Dessa vez, não por uma escassez natural, e, sim, gerada pelo próprio desenvolvimento das forças produtivas ${ }^{\mathbf{1 6}}$.

A partir dessa contradição imanente e pela compressão da realidade pela perspectiva totalizante, a dialética da saúde-doença da classe trabalhadora do campo é concebida por uma determinação social1". Em outras palavras, a saúde é intrinsicamente determinada por essas modalidades de exploração e das condições de vida deterioradas, sendo estas impostas pela natureza do Estado mediatizada pela violência de classe.

Ora, nessas condições a saúde, enquanto entendida como necessidade radical derivada da ontologia do ser social ${ }^{33}$, torna-se uma impossibilidade. De fato, uma das consequências da sociabilidade burguesa é o giro antropológico entre a mercadoria e o gênero humano ${ }^{38}$ : o trabalhador do campo é alienado do produto de seu trabalho, e as relações que orientam essa produção são mistificadas. Pouco se pode falar em consenso e cidadania em um ambiente de uso tão irrestrito da violência de classe; não é uma realidade 'virtual', é o meio pelo qual a classe trabalhadora é tragada para o capitalismo dependente.

Assim, ao reconhecermos a centralidade da questão agrária como fundamento da 
inserção dependente do Brasil ao imperialismo internacional é que nos parece premente que a Reforma Sanitária retome a análise da questão agrária como foco de crítica e ação anticapitalista. Sabe-se que, tradicionalmente, o campo da saúde coletiva ${ }^{37}$ vem tematizando a questão agrária, mas ainda em uma perspectiva de tomar como inevitável o modo de produção capitalista no campo e ainda, por vezes, desvinculá-lo de uma análise da totalidade social, tal qual estamos empreendendo neste ensaio. De fato, não é de estranhar que o campo da saúde coletiva não tangencie as relações de produção, natureza de Estado e o regime político sobre a determinação social da saúde. Este campo ainda enfoca sua produção em temas de investigação, como: ações relacionadas com a saúde e o meio ambiente em escolas, ações de formação em saúde ambiental, ações de formação que envolvem jovens e mulheres no marco da reforma agrária, produção saudável e o cuidado desenvolvido por profissionais de saúde para a população rural ${ }^{39}$.

Ora, entendemos a importância dos enfoques de pesquisa referidos acima, mas sua insistência torna insuficiente o debate sobre a relação campo-capitalismo tão necessário para repensar os rumos da Reforma Sanitária. Ao desconsideramos a dinâmica da dependência e o papel que o Estado desempenha como (re) produtor das relações capitalistas nos países subdesenvolvidos, reduz-se a análise. Se assim for, há o reforço do descolamento da questão agrária como uma variável explicativa (traduzida como um 'fator ambiental' ou 'ecológico') e esvaziando-a da centralidade na conformação da sociabilidade capitalista, posição que não condiz com a totalidade da dinâmica de acumulação no capitalismo contemporâneo. O que, de certa maneira, pode transformar a saúde no campo em uma questão de técnica e avanços parciais por meio de políticas públicas ambientais e de saúde ${ }^{37}$ (o que é importante), mas não suficiente para avançar na crítica antissistêmica.

Dessa maneira, ante o exposto, podemos formular algumas perguntas: de que maneira a tática e a estratégia do movimento da Reforma
Sanitária poderia influir sobre a saúde da classe trabalhadora situada no campo? A ocupação das instituições do aparelho de Estado pode alterar esta estrutura determinada pela própria natureza do Estado capitalista?

Compreendemos que a cidadania, enquanto tática e estratégia derivada da democracia enquanto valor universal é necessária, porém insuficiente por não adentrar no cerne da questão sobre as relações de exploração e saúde no campo. A cidadania como estratégia equaliza os modos de legitimação do Estado de países desenvolvidos com os subdesenvolvidos, e, portanto, desconsidera mediações importantes sobre os regimes políticos de legitimidade restrita e suas funções em países como o Brasil. Além disso, minora a essência violenta do Estado na realidade concreta como um instrumento essencial para a acumulação capitalista em países dependentes.

Entretanto, apesar dos avanços do movimento sanitário, a mera ocupação dos aparelhos de Estado sem sua 'quebra'4, levou à burocratização do movimento e à desmobilização de sua, já pequena, base popular. Portanto, sem uma perspectiva totalizante da saúde enquanto necessidade radical, e que, necessariamente, perpassa uma posição política anticapitalista $^{40}$, estamos fadados à burocratização e ao alijamento das demandas e necessidades das classes dominadas. Certamente, essas não se resumem aos ditames da técnica e dos cargos institucionais.

\section{Considerações finais}

Ante o exposto, o presente ensaio procurou fomentar um debate sobre as formulações acerca da natureza do Estado, a categoria 'cidadania' e suas especificidades em países subdesenvolvidos e de inserção dependente, utilizando, para isso, do percurso crítico para analisar a práxis da Reforma Sanitária sobre as relações entre saúde e questão agrária no Brasil.

A partir desse mote, realizou-se um resgate das elaborações teóricas da teoria marxista da 
dependência e da análise de Mathias e Salama, com intuito de qualificar o debate sobre as especificidades particulares da dependência e subdesenvolvimento do capitalismo no Brasil e América Latina e como a questão agrária é central nesse debate.

O Estado tratado pela principal intelectual da Reforma o considera como um lócus privilegiado para a luta de classes, não um 'comitê de negócios da burguesia'. Em que pese à relevância de sua reflexão para o período conjuntural em que se encontrava, esta mesma reflexão não desenvolve as especificidades da natureza do Estado em países subdesenvolvidos e dependentes como o Brasil, o que nos coube avançar nessa questão.

Outro aspecto fundamental que consideramos avançar é a mistificação da violência enquanto uma realidade 'virtual', sendo que a violência de classe é o meio pelo qual o regime político - seja esse ditatorial ou não - legitima-se em países como o nosso. Portanto, a categoria cidadania advinda pela expansão da democracia apresenta limitações para com a interpretação da questão agrária na totalidade social do capitalismo no Brasil, e, por isso, tratá-la com o aporte desenvolvido neste ensaio pode oportunizar a Reforma Sanitária a retomar a sua radicalidade, aprofundando a autocrítica sobre suas posições teóricas e práticas.

\section{Colaboradores}

Alves DFA (0000-0003-0080-1919)*, Carnut L (0000-0001-6415- 6977)* e Mendes A (00000002-5632-4333)* contribuíram igualmente na elaboração do manuscrito.

\section{Referências}

1. Paim JS. Reforma sanitária brasileira: contribuição para a compreensão e crítica. Salvador: EDUFBA: Rio de Janeiro: Fiocruz; 2008.

\footnotetext{
Dantas AV. Reforma Sanitária Brasileira: ainda em busca de uma teoria para um debate necessário. In: Dantas AV. Do socialismo à democracia: tática estratégia na reforma sanitária brasileira. Rio de Janeiro: Fiocruz; 2018. p. 149-203.
}

3. Teixeira SF. Reflexões teóricas sobre democracia e reforma sanitária. In: Teixeira SF, organizador. Reforma sanitária: em busca de uma teoria. São Paulo: Cortez; 1989. p. 17-46.

4. Oliveira JA. Para uma teoria da Reforma Sanitária Brasileira: "democracia progressiva” e políticas sociais. In: Fleury S, Bahia L, Amarante P, organizadores. Saúde debate: fundamentos da Reforma Sanitária. Rio de Janeiro: Cebes; 2008.
${ }^{\star}$ Orcid (Open Researcher and Contributor ID). 
5. Escorel S. Reviravolta na Saúde: origem e articulação do movimento sanitário. Rio de Janeiro: Fiocruz; 1999.

6. Arouca S. O dilema preventivista: contribuições para a compreensão e crítica da medicina preventiva. São Paulo: Unesp: Rio de Janeiro: Fiocruz; 2003.

7. Gerschman SA. A democracia inconclusa: um estudo da Reforma Sanitária Brasileira. Rio de Janeiro: Fiocruz; 2004.

8. Fleury S. Estado sem cidadãos: seguridade social na América Latina. Rio de Janeiro: Fiocruz; 1994.

9. Coutinho CN. A democracia como valor universal. In: Silveira E, organidor. Encontros com a Civilização Brasileira. Rio de Janeiro: Civilização Brasileira; 1979. p. $33-47$

10. Neves V. Estratégica democrática em Carlos Nelson Coutinho. In: Iasi M, Figueiredo IM, Neves V. A estratégia democrático-popular: um inventário crítico. Marília: Lutas Anticapital; 2019. p. 205-225.

11. Breilh J. Epidemiologia crítica: ciência emancipadora e interculturalidade. Rio de Janeiro: Fiocruz; 2006.

12. Marini RM. Dialética da dependência. In: Stedile JP, Traspadini R, organizadores. Ruy Mauro Marini: vida e obra. 2. ed. São Paulo: Expressão Popular; 2011. p. 131-172.

13. Luce MS. Teoria marxista da dependência: problemas e categoria - uma visão histórica. São Paulo: Expressão Popular; 2018.

14. Wood EM. A separação entre o "econômico" e o "político" no capitalismo. In: Wood ME. Democracia contra capitalismo: a renovação do materialismo histórico. São Paulo: Boitempo; 2011. p. 27-50.

15. Marx K. Crítica da filosofia do direito de Hegel. 3. ed. São Paulo: Boitempo; 2013.

16. Mathias G, Salama P. O Estado superdesenvolvido: ensaios sobre a intervenção estatal e sobre as for- mas de dominação no capitalismo contemporâneo. São Paulo: Brasiliense; 1983.

17. Anderson P. Linhagens do Estado absolutista. São Paulo: Unesp; 2016.

18. Marx K. O capital: crítica da economia política: livro 1 - o processo de produção do capital. 2. ed. São Paulo: Boitempo; 2017.

19. Pachukanis EB. Teoria geral do direito e marxismo. São Paulo: Boitempo; 2017.

20. Marx K. Sobre a questão judaica. São Paulo: Boitempo; 2010.

21. Mariátegui JC. O problema da terra. In: Mariátegui JC. Sete ensaios de interpretação da realidade peruana. 2. ed. São Paulo: Expressão Popular; 2010. p. 67113.

22. Fanon F. Os condenados da terra. Minas Gerais: UFJF; 2006.

23. Moraes JQ. Contra a canonização da democracia. Crítica Marxista [internet]. 2001 [acesso em 2019 maio 25]; 12:9-40. Disponível em: https://www.ifch.unicamp.br/criticamarxista/arquivos_biblioteca/artigo7101quarti.pdf.

24. Sampaio Jr PA. Desenvolvimentismo e neodesenvolvimentismo: tragédia e farsa. Ser. soc. soc. [internet]. 2012 [acesso em 2019 maio 25]; 112:672-688. Disponível em: http://www.scielo.br/pdf/sssoc/n112/04.pdf

25. Demier F. Depois do golpe: a dialética da democracia blindada no Brasil. Rio de Janeiro: Mauad; 2017.

26. Netto JP, Braz M. O imperialismo. In: Netto J, Braz M. Economia Política: uma introdução crítica. 8. ed. São Paulo: Cortez; 2012. p. 181-222.

27. Fernandes F. Capitalismo dependente e classes sociais na América Latina. São Paulo: Globo; 2009.

28. Ianni O. A Idéia de Brasil Moderno. São Paulo: Brasiliense; 1992. 
29. Oliveira F. Crítica à razão dualista: o ornitorrinco. São Paulo: Boitempo; 2013.

30. Hillani A. As violências do Capital. In: Anais do II Seminário Nacional de Teoria Marxista: o capitalismo e suas crises; 2016 maio; Uberlândia. Uberlândia: Pueblo Editora; 2016. p. 1-13.

31. Iasi ML. Reflexão sobre o processo de consciência. In: Iasi ML. Ensaios sobre a consciência e emancipação. 2. ed. São Paulo: Expressão Popular; 2011. p. $11-46$.

32. Chasin J. Marx: estatuto ontológico e resolução metodológica. São Paulo: Boitempo; 2009.

33. Mendes-Gonçalves RB. Práticas de saúde: processos de trabalho e necessidades. São Paulo: Secretaria Municipal de Saúde; 1992.

34. Lessa S, Tonet I. Introdução à filosofia de Marx. 2. ed. São Paulo: Expressão Popular; 2011.

35. Prado Jr C. A questão agrária no Brasil. São Paulo: Companhia das Letras; 2014.
36. Stotz EN. A "questão agrária” e a saúde pública: considerações em torno de uma crítica ao neoliberalismo. Ciênc. Saúde Colet. 2007 [internet]. [acesso em 2019 maio 25]; 12(1):15-24. Disponível em: http:// www.scielo.br/pdf/csc/v12nl/03a.pdf.

37. Delgado G. Questão Agrária e Saúde. Rio de Janeiro: Cebes; 2012.

38. Márkus G. Marxismo e Antropologia: o conceito de 'essência humana' na filosofia de Marx. São Paulo: Expressão Popular; 2015.

39. Rückert B, Aranha AVS. Lutar por saúde é lutar por reforma agrária: estudo sobre práticas de saúde no Movimento dos Trabalhadores Rurais Sem Terra. Saúde e Soc. 2018 [internet]. [acesso em 2019 maio 25]; 27(1):116-127. Disponível em: http://www.scielo.br/ pdf/sausoc/v27nl/1984-0470-sausoc-27-01-116.pdf.

40. Ferrara FA. Teoría social y salud. Bueno Aires: Catalogos; 1985.

Recebido em 03/06/2019

Aprovado em 01/09/2019

Conflito de interesses: inexistente

Suporte financeiro: não houve 